\title{
On the pressure and temperature dependence of ordering temperature and magnetization of $\mathrm{Y}_{1-\mathrm{x}} \mathrm{Th}_{\mathrm{x}} \mathrm{Co}_{4} \mathrm{~B}$ compounds
}

\author{
H. Mayot, ${ }^{1}$ O. Isnard, ${ }^{1,2, a)}$ Z. Arnold, ${ }^{3}$ and J. Kamarad ${ }^{3}$ \\ ${ }^{1}$ Institut Néel du CNRS, associé à l'Université Joseph Fourier, BP166X, F-38042 Grenoble Cédex 9, \\ France \\ ${ }^{2}$ Institut Universitaire de France, Maison des Universités, 103 Boulevard Saint Michel, 75005 Paris, France \\ ${ }^{3}$ Institute of Physics AS CR, v.v.i., Na Slovance 2, 18221 Praha 8, Czech Republic
}

(Received 25 December 2009; accepted 6 April 2010; published online 26 May 2010)

\begin{abstract}
We present here a detailed investigation of the pressure dependence of the structural and magnetic properties in a wide temperature range from 5 to $340 \mathrm{~K}$ for the $\mathrm{Y}_{1-\mathrm{x}} \mathrm{Th}_{\mathrm{x}} \mathrm{Co}_{4} \mathrm{~B}$ series. The unit cell lattice compressibility has been determined from powder neutron diffraction technique in the 0 to $0.5 \mathrm{GPa}$ pressure range. Substitution of Th for $\mathrm{Y}$ is found to reduce significantly the compressibility. The Curie temperature decreases dramatically upon the Th for Y substitution. Studies were performed on polycrystalline samples under hydrostatic pressure up to $1.1 \mathrm{GPa}$ and in magnetic field up to $5 \mathrm{~T}$. The evolution of the saturation magnetization under pressure is presented as well as the pressure dependence of the Curie temperature. Remarkable pressure effects on the Curie temperature and on the critical field at which the first order magnetization process occurs for $\mathrm{Y}_{0.8} \mathrm{Th}_{0.2} \mathrm{Co}_{4} \mathrm{~B}$ are analyzed and discussed. The pressure derivatives values of both the Curie temperature and the magnetization are negative for all the studied compounds. This is an opposite tendency than that expected from chemical pressure effects. This supports the dominant role of valence electrons in the magnetic properties of the substituted $\mathrm{Y}_{1-\mathrm{x}} \mathrm{Th}_{\mathrm{x}} \mathrm{Co}_{4} \mathrm{~B}$ compound in the case of the chemical pressure effect. The magnetization and the Curie temperature exhibit different pressure dependence along the $\mathrm{Y}_{1-\mathrm{x}} \mathrm{Th}_{\mathrm{x}} \mathrm{Co}_{4} \mathrm{~B}$ series of compounds. () 2010 American Institute of Physics. [doi:10.1063/1.3418445]
\end{abstract}

\section{INTRODUCTION}

Among the wide family of rare-earth $(\mathrm{R})$ transition metal (M) intermetallic, the $\mathrm{R}_{n+1} \mathrm{Co}_{3 n+5} \mathrm{~B}_{2 n}$ compounds, where $\mathrm{R}$ represents a lanthanide, form a physically interesting class of materials because they crystallize in the same space group and can be simply derived from the $\mathrm{RCo}_{5}$ structure type. ${ }^{1-8}$ The compounds are obtained by the ordered substitution of boron for cobalt in $\mathrm{RCo}_{5}(n=0)$. For $n=1\left(\mathrm{RCo}_{4} \mathrm{~B}\right)$, a superstructure of the $\mathrm{RCo}_{5}$ one is obtained leading to a doubling of the unit cell. ${ }^{1-11}$ Compounds of this series are known to exhibit interesting magnetic properties which have motivated intensive research during the last years. ${ }^{6,11-21}$ Since their discovery, the $\mathrm{RCo}_{4} \mathrm{~B}$ compounds have attracted much interest since they exhibit unusually large magnetocrystalline anisotropy. ${ }^{16,22,23}$ Furthermore, the isotype $\mathrm{RCo}_{4} \mathrm{~B}$ compounds with nonmagnetic $\mathrm{R}$ elements such as $\mathrm{La}, \mathrm{Lu}$, and $\mathrm{Y}$ exhibit unique magnetic properties governed by the Co sublattice only. Due to a competition between two inequivalent Co atomic positions, the spin reorientation transition and the first order magnetization process (FOMP) have been found in $\mathrm{YCo}_{4} \mathrm{~B}$ compound. Such behavior has been studied in details by magnetic measurements, ${ }^{9,24-26}$ neutron diffraction investigation, ${ }^{3,9}$ Mossbauer spectroscopy, ${ }^{27-29} \mathrm{NMR}^{30}$ or band structure calculations. ${ }^{31}$ More recently $\mathrm{ThCo}_{4} \mathrm{~B}$ isotype compound has been discovered. ${ }^{32}$ Substituting nonmagnetic Th for $\mathrm{Y}$ in $\mathrm{YCo}_{4} \mathrm{~B}$, volume of the elemental crystal unit cell

\footnotetext{
${ }^{a)}$ Author to whom correspondence should be addressed. Electronic mail: olivier.isnard@grenoble.cnrs.fr.
}

increases by $4 \%$ and magnetic properties are remarkably changed, e.g., the Curie temperature $T_{\mathrm{C}}$ is lowered by $20 \%$ and saturation magnetization $M_{\mathrm{S}}$ is reduced by more than $40 \% .^{32}$ In order to understand deeper the Co sublattice magnetic properties, we present here results of a study of both the chemical and the hydrostatic pressure effects on magnetic properties of the $\mathrm{Y}_{1-\mathrm{x}} \mathrm{Th}_{\mathrm{x}} \mathrm{Co}_{4} \mathrm{~B}$ compound series. The magnetic properties of $\mathrm{YCo}_{4} \mathrm{~B}$ have been investigated in details by Thang and co-workers ${ }^{243}$ as well as the pressure dependence of these magnetic properties. ${ }^{22,25,26}$ Pressure studies were performed on polycrystalline samples under hydrostatic pressure. More recently, the complexity of the magnetic phase diagram of $\mathrm{YCo}_{4} \mathrm{~B}$ has motivated an extensive study of the magnetocrystalline behavior of this compound. ${ }^{22}$ Due to the recent discovery of the Th containing compounds, fewer studies have been devoted to these compounds. ${ }^{34}$ Following these earlier works, we report here on the pressure and temperature dependence of the magnetic properties of the polycrystalline $\mathrm{Y}_{1-\mathrm{x}} \mathrm{Th}_{\mathrm{x}} \mathrm{Co}_{4} \mathrm{~B}$ compounds in order to deeper investigate the unusual magnetic properties of these compounds.

\section{EXPERIMENTAL}

\section{A. Synthesis and magnetic measurements}

Polycrystalline samples of $\mathrm{Y}_{1-\mathrm{x}} \mathrm{Th}_{\mathrm{x}} \mathrm{Co}_{4} \mathrm{~B}$ compounds have been prepared by arc melting technique in a cold copper crucible under an argon atmosphere, using elements of purity better than $99.9 \%$ for $\mathrm{Y}$ and Co and $99.8 \%$ for B. For better homogeneity, the samples were wrapped in a Ta foil 
and subsequently annealed at $1173 \mathrm{~K}$ for a week in an evacuated quartz tube. The samples purity has been checked by using the JEOL 840A scanning electron microscope equipped with the KEVEX energy dispersive X-ray analysis (EDX) microprobe. Structure of the samples has been checked by X-ray diffraction.

\section{B. Magnetic measurements under high pressure}

The magnetization curves of $\mathrm{Y}_{1-\mathrm{x}} \mathrm{Th}_{\mathrm{x}} \mathrm{Co}_{4} \mathrm{~B}$ samples were recorded at ambient pressure by the extraction method ${ }^{35}$ in a magnetic field up to $10 \mathrm{~T}$. The magnetization measurements at high hydrostatic pressure up to about $1 \mathrm{GPa}$ were performed in a superconducting quantum interference device magnetometer (Quantum Design Co.) in magnetic fields up to $5 \mathrm{~T}$ in the temperature range from $5 \mathrm{~K}$ to $300 \mathrm{~K}$ using a miniature pressure cell. The Curie temperature $T_{\mathrm{C}}$ under different pressures was determined from temperature dependence of dc susceptibility measured in a magnetic field 10 $\mathrm{mT}$ with a heating rate of $1 \mathrm{~K}$ per minute. The saturation magnetization at different pressures was determined from the isothermal magnetization curves.

The miniature piston-cylinder $\mathrm{CuBe}$ pressure cell was filled with a mixture of mineral oils as a pressure transmitting medium. The pressure was determined at low temperatures using the known pressure dependence of the critical temperature of the superconducting state of the $\mathrm{Pb}$ sensor placed inside the cell. ${ }^{36}$ The actual pressure values for the isothermal magnetization curves were determined taking into account the temperature induced changes of the pressure inside the cell. For the temperature dependent measurements, the given pressure value corresponds to the pressure value at transition temperature.

\section{Neutron diffraction experiments}

The room temperature diffraction patterns have been measured on the instrument D1B operated by the CNRS at the ILL. On the D1B instrument, the diffraction patterns have been recorded over an angular range of $80^{\circ}(2 \theta)$ using a multidetector with a step of $0.2^{\circ}$ between each of the 400 ${ }^{3} \mathrm{He}$ detection cells. D1B is a two-axis powder diffractometer destined for diffraction experiments requesting a high neutron flux. Three pyrolitic graphite monochromators focused onto the sample position provide a flux of neutrons 6.5 $\times 10^{6} \mathrm{n} \mathrm{cm}^{-2} \mathrm{~s}^{-1}$ with wavelength $\lambda=2.52 \AA$. The take off angle is $44.2^{\circ}$ in $2 \theta$. In the Helium loaded high pressure cell used here, the pressure can be continuously adjusted from 0 to $0.5 \mathrm{GPa}$ while the cell with a sample is in the beam. The cell is linked via a flexible high pressure capillary to a gas pressure generator, or a high pressure piston pump. Helium gas is used as the pressure transmitting medium for pressures up to $0.5 \mathrm{GPa}$. Pressure is determined by standard oil manometer and by strain gauges fixed on the outer surface of the pressure cell. The nuclear reflections were observed together with parasitic peaks stemming from the pressure cell. Background contribution is also caused by the incoherent scattering of the gas pressure cell which volume is much larger than volume of the sample. The lattice parameters

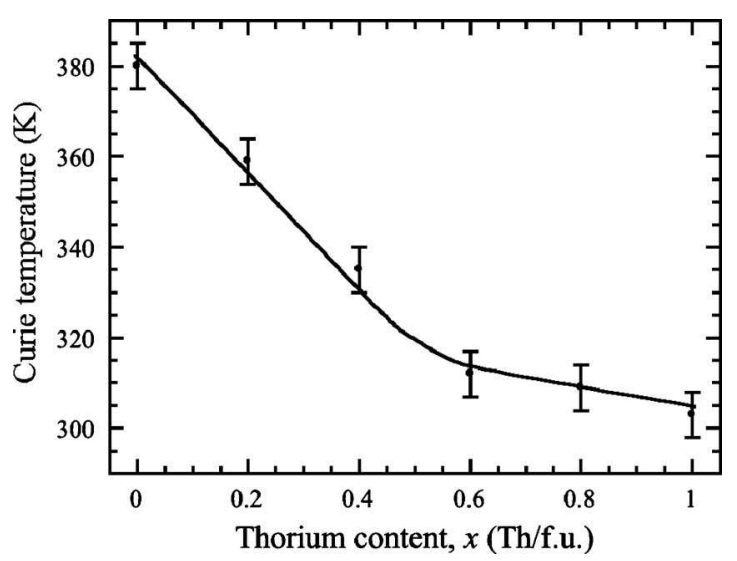

FIG. 1. Evolution of the Curie temperature in the $\mathrm{Y}_{1-\mathrm{x}} \mathrm{Th}_{\mathrm{x}} \mathrm{Co}_{4} \mathrm{~B}$ compounds.

have been determined by Lebail fitting of the observed diffraction peaks of the patterns obtained after subtraction of the cryostat and pressure cell contributions.

\section{MAGNETIC MEASUREMENTS AT AMBIENT PRESSURE}

We will concentrate here on the analysis of some magnetic properties of the compounds forming the solid solution between $\mathrm{R}=\mathrm{Y}$ and $\mathrm{Th}$. The next section will be devoted to the evolution of the ordering temperatures versus composition and then an unusual magnetization process observed in $\mathrm{Y}_{0.8} \mathrm{Th}_{0.2} \mathrm{Co}_{4} \mathrm{~B}$ will be presented.

\section{A. Ordering temperature}

The ordering temperature has been investigated by thermomagnetic measurements at constant field. As can be seen from Fig. 1, the $\mathrm{Y}_{1-\mathrm{x}} \mathrm{Th}_{\mathrm{x}} \mathrm{Co}_{4} \mathrm{~B}$ compounds are exhibiting ferromagnetic behavior with an ordering temperature slightly above room temperature.

The ordering temperature is progressively decreasing upon substitution of Th for Y. This decrease (see Fig. 1) confirms the trend reported earlier for the two extreme compounds. ${ }^{32}$ This is also in favor of a solid solution behavior corresponding to the results of crystal structure investigation. ${ }^{37}$ Furthermore, it is worth to recall that the replacement of trivalent $\mathrm{Y}$ by tetravalent Th atoms has led to a strong decrease in both, the Co magnetization as well as the Curie temperature from $375 \mathrm{~K}$ to $302 \mathrm{~K}$ going from $\mathrm{YCo}_{4} \mathrm{~B}$ to $\mathrm{ThCo}_{4} \mathrm{~B}$, respectively. Values of the Curie temperature $T_{\mathrm{C}}$ of the $\mathrm{Y}_{1-\mathrm{x}} \mathrm{Th}_{\mathrm{x}} \mathrm{Co}_{4} \mathrm{~B}$ compounds are summarized in Table I.

\section{B. The first order like magnetization process}

As it has been reported, $\mathrm{YCo}_{4} \mathrm{~B}$ exhibits a peculiar behavior of its magnetic properties with a step like shape of the magnetization isotherms recorded along the crystal $c$ axis (hard magnetization direction, HMD) at low temperature or even along the $a$ axis above the spin reorientation transition. It is worth to mention that this step like magnetization curves are only observed along the hard magnetic axis. ${ }^{22,33}$ This behavior of the magnetization curves recorded along HMD has been interpreted as the FOMP that can be characterized 
TABLE I. The Curie temperature of the $\mathrm{Y}_{1-\mathrm{x}} \mathrm{Th}_{\mathrm{x}} \mathrm{Co}_{4} \mathrm{~B}$ compounds and pressure derivatives of $T_{\mathrm{C}}$ and $M_{\mathrm{S}}$.

\begin{tabular}{lcccccc}
\hline \hline \multicolumn{1}{c}{} & $\begin{array}{c}T_{\mathrm{C}} \\
(\mathrm{K})\end{array}$ & $\begin{array}{c}\mathrm{d} T_{\mathrm{C}} / \mathrm{d} P \\
(\mathrm{~K} / \mathrm{GPa})\end{array}$ & $\begin{array}{c}\mathrm{d} \ln T_{\mathrm{C}} / \mathrm{dP} \\
\left(\mathrm{TPa}^{-1}\right)\end{array}$ & $\begin{array}{c}T_{\mathrm{C}} \mathrm{d} T_{\mathrm{C}} / \mathrm{d} P \\
\left(\mathrm{~K}^{2} / \mathrm{GPa}\right)\end{array}$ & $\begin{array}{c}\mathrm{d} \ln \\
T_{\mathrm{C}} / \mathrm{d} \ln V\end{array}$ & $\begin{array}{c}\mathrm{d} \ln M_{\mathrm{S}}(5 \mathrm{~K}) / \mathrm{d} P \\
\left(\mathrm{GPa}^{-1}\right)\end{array}$ \\
\hline 0 & 375 & $-11.5(1.3)$ & $-30.7(4.0)$ & $-4310(30)$ & $4.7(2.1)$ & $-33(3) 10^{-3}$ \\
0.2 & 352 & $-9.0(1.3)$ & $-25.6(4.0)$ & $-3170(30)$ & $4.3(1.5)$ & $-29(3) 10^{-3}$ \\
0.4 & 329 & $-7.1(1.3)$ & $-21.6(4.0)$ & $-2340(30)$ & $4.0(1.2)$ & $-31(3) 10^{-3}$ \\
0.6 & 315 & $-6.8(1.2)$ & $-21.6(4.0)$ & $-2140(25)$ & $4.4(1.2)$ & $-32(4) 10^{-3}$ \\
0.8 & 309 & $-3.8(12)$ & $-12.3(4.5)$ & $-1170(25)$ & $2.9(0.7)$ & $-33(4) 10^{-3}$ \\
1 & 302 & $-4.0(12)$ & $-13.2(4.5)$ & $-1210(25)$ & $3.5(1.8)$ & $-32(4) 10^{-3}$ \\
\hline \hline
\end{tabular}

by a critical field at which the magnetization increases rapidly with the increasing applied field. This FOMP like behavior of $\mathrm{YCO}_{4} \mathrm{~B}$ has been extensively studied elsewhere. ${ }^{22,24,33}$ The present investigation reveals that $\mathrm{Y}_{0.8} \mathrm{Th}_{0.2} \mathrm{Co}_{4} \mathrm{~B}$ is the only Th containing compound of the $\mathrm{Y}_{1-\mathrm{x}} \mathrm{Th}_{\mathrm{x}} \mathrm{Co}_{4} \mathrm{~B}$ series exhibiting similar unusual behavior reminiscent to the behavior of the $\mathrm{YCo}_{4} \mathrm{~B}$ parent compound. This FOMP-like behavior of $Y_{0.8} \mathrm{Th}_{0.2} \mathrm{Co}_{4} \mathrm{~B}$ is clearly seen in Figs. 2 and 3. Here we take magnetic field where the maximum value of the field derivative of the magnetization curves is reached as the critical field of the FOMP, see Fig. 3. The critical field evolves when the temperature increases, as can be seen from Fig. 3. The critical field increases up to $2.5 \mathrm{~T}$ for $\mathrm{Y}_{0.8} \mathrm{Th}_{0.2} \mathrm{Co}_{4} \mathrm{~B}$ thus approaching the anisotropy field. Consequently, this FOMPlike magnetization process has even completely disappeared at $100 \mathrm{~K}$. It is remarkable that unlike $\mathrm{YCo}_{4} \mathrm{~B}$ which presents a spin reorientation of its magnetization direction, $\mathrm{Y}_{0.8} \mathrm{Th}_{0.2} \mathrm{Co}_{4} \mathrm{~B}$ does not exhibit that. ${ }^{37}$ Indeed, no anomalous behavior has been observed on the susceptibility measurements ruling out the possibility of such transition. The behavior of $\mathrm{Y}_{0.8} \mathrm{Th}_{0.2} \mathrm{Co}_{4} \mathrm{~B}$ is similar to that observed previously for $\mathrm{YCo}_{4} \mathrm{~B}$ above the spin reorientation since in both cases the critical field increases with increasing temperature.

The overall magnetocrystalline energy of $\mathrm{YCo}_{4} \mathrm{~B}$ results from the competition of two contributions arising from the Co ions at the two crystal $2 \mathrm{c}$ and $6 \mathrm{i}$ sites. These contributions have opposite signs and comparable magnitudes. ${ }^{22,24,30,33}$ Consequently, the disappearance of the spin reorientation temperature upon Th for Y substitution can be interpreted as a result of the balance between these two sublattice anisotropy. Unlike the 2c Co-sites which keep about the same

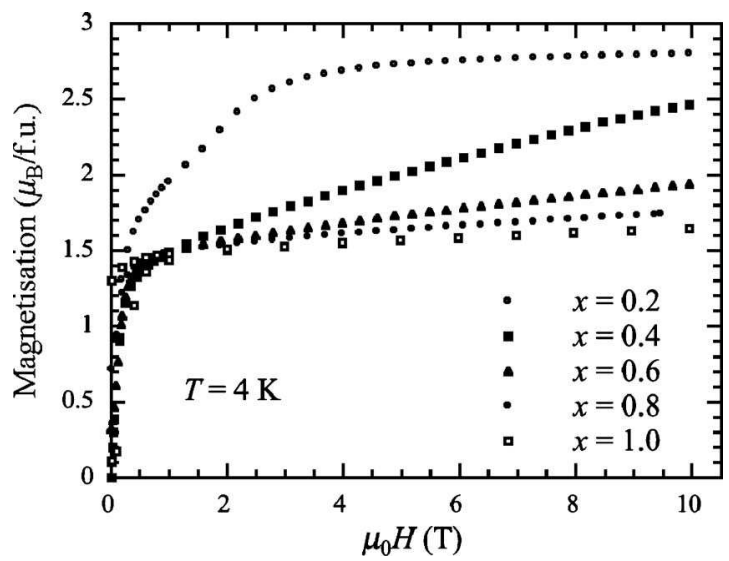

FIG. 2. Isothermal magnetization curves of the $\mathrm{Y}_{1-\mathrm{x}} \mathrm{Th}_{\mathrm{x}} \mathrm{Co}_{4} \mathrm{~B}$ polycrystalline bulk samples at atmospheric pressure. magnetic moment in both compounds, $\mathrm{ThCo}_{4} \mathrm{~B}$ and $\mathrm{YCo}_{4} \mathrm{~B},{ }^{19,32}$ the $6 \mathrm{i}$ Co-sites magnetization has been found to be significantly reduced in the $\mathrm{ThCo}_{4} \mathrm{~B}$ compound. One can thus expect a strong reduction in the 6i Co-sites contribution to the magnetocrystalline anisotropy, a reduction which contributes to the disappearance of the spin reorientation upon replacing $\mathrm{Y}$ by Th atoms. At this point, it is worth to remind that the magnetic moment of the $\mathrm{Co3g}$ site in tetravalent ( $\mathrm{Th}, \mathrm{Ce}) \mathrm{Co}_{5}$ compounds has been reported to be low and unstable. ${ }^{38}$ In this context and bearing in mind the structural relationship between the $\mathrm{Co} 3 \mathrm{~g}$ and Co 6i positions in $\mathrm{RCo}_{5}$ and $\mathrm{RCo}_{4} \mathrm{~B}$ structures, respectively, the reduced value of the Co 6i magnetic moment in $\mathrm{ThCo}_{4} \mathrm{~B}$ may be taken as reminiscent of the $\mathrm{RCo}_{5}$ behavior.
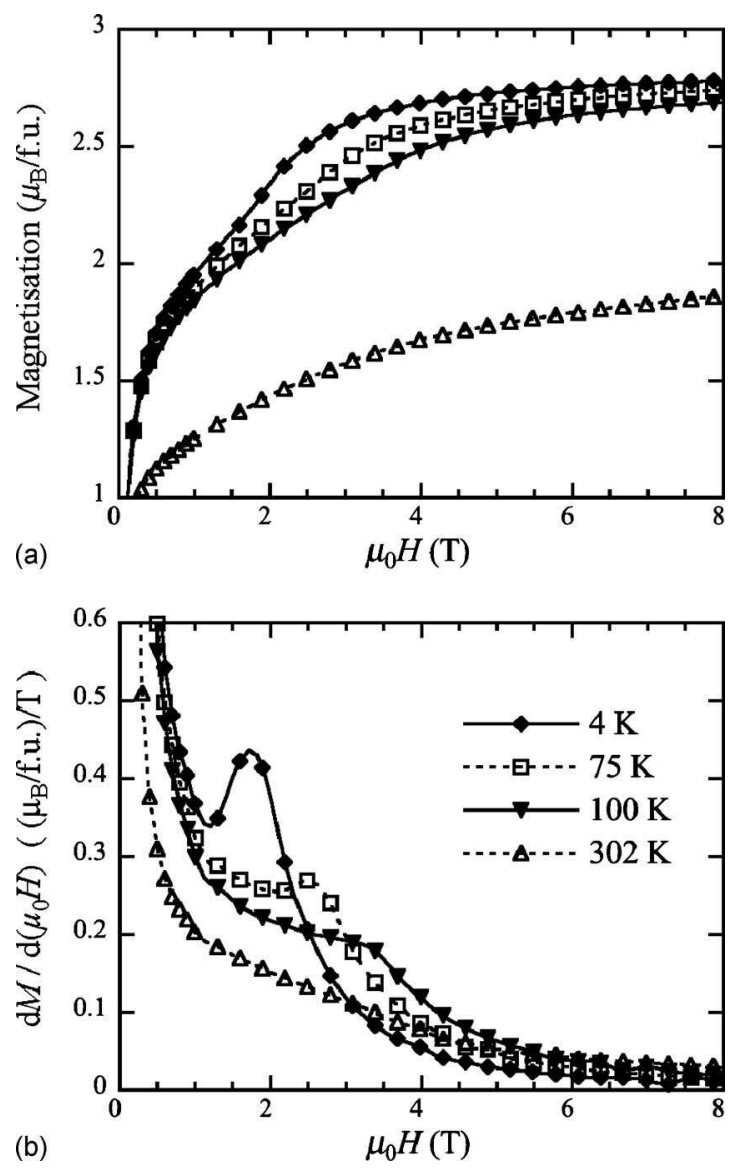

FIG. 3. (a) Isothermal magnetization curves of $\mathrm{Y}_{0.8} \mathrm{Th}_{0.2} \mathrm{Co}_{4} \mathrm{~B}$ polycrystalline sample at ambient pressure. (b) Temperature evolution of the field derivatives of magnetization showing the critical field of the magnetic first order process at indicated temperatures. 
TABLE II. Pressure evolution of the $\mathrm{Y}_{1-\mathrm{x}} \mathrm{Th}_{\mathrm{x}} \mathrm{Co}_{4} \mathrm{~B}$ compounds lattice parameters deduced from powder neutron diffractions under pressures 0 and $0.5 \mathrm{GPa}$.

\begin{tabular}{lcccccc}
\hline \hline Composition & $\begin{array}{c}\mathrm{d} a / \mathrm{d} P \\
(\AA / \mathrm{APa})\end{array}$ & $\begin{array}{c}\mathrm{d} c / \mathrm{d} P \\
(\AA / \mathrm{TPa})\end{array}$ & $\begin{array}{c}\mathrm{d} V / \mathrm{d} P \\
\left(\AA^{3} / \mathrm{GPa}\right)\end{array}$ & $\begin{array}{c}\mathrm{d}(\ln a) / \mathrm{d} P \\
\left(\mathrm{TPa}^{-1}\right)\end{array}$ & $\begin{array}{c}\mathrm{d}(\ln c) / \mathrm{d} P \\
\left(\mathrm{TPa}^{-1}\right)\end{array}$ & $\begin{array}{c}\mathrm{d}(\ln V) / \mathrm{d} P \\
\left(\mathrm{TPa}^{-1}\right)\end{array}$ \\
\hline $\mathrm{Y}_{0.8} \mathrm{Th}_{0.2} \mathrm{Co}_{4} \mathrm{~B}$ & $-11(1)$ & $-13(4)$ & $-0.9(1)$ & $-2.2(4)$ & $-1.8(6)$ & $-6.2(8)$ \\
$\mathrm{Y}_{0.2} \mathrm{Th}_{0.8} \mathrm{Co}_{4} \mathrm{~B}$ & $-5.5(5)$ & $-15(2)$ & $-0.66(5)$ & $-1.1(1)$ & $-2.1(2)$ & $-4.3(3)$ \\
\hline \hline
\end{tabular}

The magnetization isotherms recorded at $4 \mathrm{~K}$ for the $\mathrm{Y}_{1-\mathrm{x}} \mathrm{Th}_{\mathrm{x}} \mathrm{Co}_{4} \mathrm{~B}$ compounds are significantly exhibiting different magnetic behavior. The low magnetization obtained for the Th rich compounds may be indicative of the occurrence of instability of the magnetic moment. Indeed, as said above, itinerant metamagnetic behavior has been reported for the related $\mathrm{RCo}_{5}$ phase $(\mathrm{R}=\mathrm{Th}, \mathrm{Ce})$, leading to low magnetic state and metamagnetic transition under high applied fields from the small moment to the large moment state. ${ }^{38-40}$ The Co atoms in this compound occupy two sites, $2 \mathrm{c}$ and $3 \mathrm{~g}$. It was found by the band calculation ${ }^{40}$ that the Co atoms at the $3 \mathrm{~g}$ site are nonmagnetic without magnetic field, while the Co atoms at the $2 \mathrm{c}$ site are magnetic. High magnetic field measurements would be useful to check the possible occurrence of metamagnetic behavior in Th rich $\mathrm{Y}_{1-\mathrm{x}} \mathrm{Th}_{\mathrm{x}} \mathrm{Co}_{4} \mathrm{~B}$ compounds.

In $\mathrm{Y}_{0.8} \mathrm{Th}_{0.2} \mathrm{Co}_{4} \mathrm{~B}$, the disappearance of the steplike magnetization curves above $220 \mathrm{~K}$ may originate from the overall change in the magnetocrystalline anisotropy parameters upon increasing temperature. Indeed, the increase in the critical field may lead to a cross over with the anisotropy field thus leading to the disappearance of the observed FOMP-like in the magnetocrystalline isotherms. The presence of FOMP in the magnetization curves requires certain conditions concerning the anisotropy constant that must be fulfilled-see the articles of Asti and Bolzoni for more details. ${ }^{41-43} \mathrm{~A}$ detailed investigation of the anisotropy parameters of these $\mathrm{Y}_{1-\mathrm{x}} \mathrm{Th}_{\mathrm{x}} \mathrm{Co}_{4} \mathrm{~B}$ compounds is out of the scope of the present paper since such study requires single crystal samples and high magnetic field to enable the adequate saturation of the sample.

\section{PRESSURE EFFECTS}

The pressure effects on magnetic properties of $\mathrm{RCo}_{4} \mathrm{~B}$ compounds ${ }^{22,25,26,34,44}$ have attracted our interest in the last several years. Following these earlier measurements, we investigate and analyze successively the evolution of the ordering temperature, the magnetization, and the possible occurrence of the FOMP anomalies in the magnetic properties of the $\mathrm{Y}_{1-\mathrm{x}} \mathrm{Th}_{\mathrm{x}} \mathrm{Co}_{4} \mathrm{~B}$ compounds. After the description of the pressure effect on the crystal lattice, Secs. IV A-IV D will be devoted to the influence of pressure on the crystal structure and the intrinsic magnetic properties of these compounds starting from the crystal lattice, followed by the Curie temperature then by the magnetization and finally by the critical field of FOMP.

\section{A. Pressure effects on the crystal lattice}

Two samples have been selected for the investigation of the effect of pressure on their lattice: $\mathrm{Y}_{0.8} \mathrm{Th}_{0.2} \mathrm{Co}_{4} \mathrm{~B}$ and $\mathrm{Y}_{0.2} \mathrm{Th}_{0.8} \mathrm{Co}_{4} \mathrm{~B}$. The neutron diffraction experiments have been undertaken at room temperature. Table II presents the pressure dependence of the lattice parameters of these two compounds. The pressure induced reduction in the unit cell volume is much smaller for the Th rich compound than for the $\mathrm{Y}$ rich one, showing the influence of the $\mathrm{R}$ element nature on the compressibility of the lattice. According to earlier studies, the values of compressibility, $\kappa=-\mathrm{d} \ln V / \mathrm{d} P$, are almost the same along the $\mathrm{RCo}_{4} \mathrm{~B}$ compound series whatever the rare-earth element is used. The value of $7.4 \mathrm{TPa}^{-1}$ has been reported for $\mathrm{CeCo}_{4} \mathrm{~B} .{ }^{26}$ The values calculated here for $\mathrm{Y}_{1-\mathrm{x}} \mathrm{Th}_{\mathrm{x}} \mathrm{Co}_{4} \mathrm{~B}$ are much smaller, 6.2 and 4.3 for $\mathrm{x}=0.2$ and 0.8 , respectively, bearing witness to the influence of a large atom like Th on the intermetallic compound compressibility. It is worth to note that in spite of the known intermediate valence state of $\mathrm{Ce}$ between the trivalent and tetravalent state, the compressibility of the $\mathrm{CeCo}_{4} \mathrm{~B}$ compound does not correspond here to an intermediate case between the compressibility of $\mathrm{Y}$ rich and Th rich $\mathrm{Y}_{1-\mathrm{x}} \mathrm{Th}_{\mathrm{x}} \mathrm{Co}_{4} \mathrm{~B}$ compounds. As it is seen from Figs. 4 and 5, a continuous reduction in the lattice parameters of both investigated compounds, with $\mathrm{x}$ $=0.2$ and 0.8 , is observed under pressure. Within error bars, their linear pressure dependence can be considered in the whole investigated pressure range.

\section{B. Pressure effects on the Curie temperature of $\mathrm{Y}_{1-\mathrm{x}} \mathrm{Th}_{\mathrm{x}} \mathrm{Co}_{4} \mathrm{~B}$ compounds}

The Curie temperature of $\mathrm{YCo}_{4} \mathrm{~B}$ has been found ${ }^{26}$ to vary under the applied pressure with the pressure coefficients $\mathrm{d} \ln T_{\mathrm{C}} / \mathrm{d} P=-3.1 \times 10^{-2} \mathrm{GPa}^{-1} \quad\left(\mathrm{~d} T_{\mathrm{C}} / \mathrm{d} P=-11.5 \mathrm{~K} / \mathrm{GPa}\right)$. We concentrate here on the $\mathrm{Y}_{1-\mathrm{x}} \mathrm{Th}_{\mathrm{x}} \mathrm{Co}_{4} \mathrm{~B}$ isotype compounds. As can be seen from Fig. 6, applying pressure induces a reduction in the Curie temperature of all the $\mathrm{Y}_{1-\mathrm{x}} \mathrm{Th}_{\mathrm{x}} \mathrm{Co}_{4} \mathrm{~B}$ compounds. The pressure coefficients of $T_{\mathrm{C}}$ are summarized in Table I.

As can be clearly seen in Fig. 7 presenting the composition dependence of the pressure coefficients is plotted, the compounds $\mathrm{Y}_{1-\mathrm{x}} \mathrm{Th}_{\mathrm{x}} \mathrm{Co}_{4} \mathrm{~B}$ with the larger Th content exhibit the substantially lower pressure dependence of the Curie temperature. On the other hand, $T_{\mathrm{C}}$ itself decreases with $\mathrm{x}$ only slightly. Values of the parameter $T_{\mathrm{C}} \mathrm{d} T_{\mathrm{C}} / \mathrm{d} P$ have been reported to be close to $4300 \pm 300 \mathrm{~K}^{2} / \mathrm{GPa}$ for the $\mathrm{RCo}_{4} \mathrm{~B}{ }^{26}$ This is a value that is well consistent with the Wolfarth's model of itinerant ferromagnetism. ${ }^{45,46}$ When substituting Th for $\mathrm{Y}$ in the $\mathrm{Y}_{1-\mathrm{x}} \mathrm{Th}_{\mathrm{x}} \mathrm{Co}_{4} \mathrm{~B}$ compounds series, the parameter $T_{\mathrm{C}} \mathrm{d} T_{\mathrm{C}} / \mathrm{d} P$ is significantly reduced by increasing $\mathrm{x}$. Such 


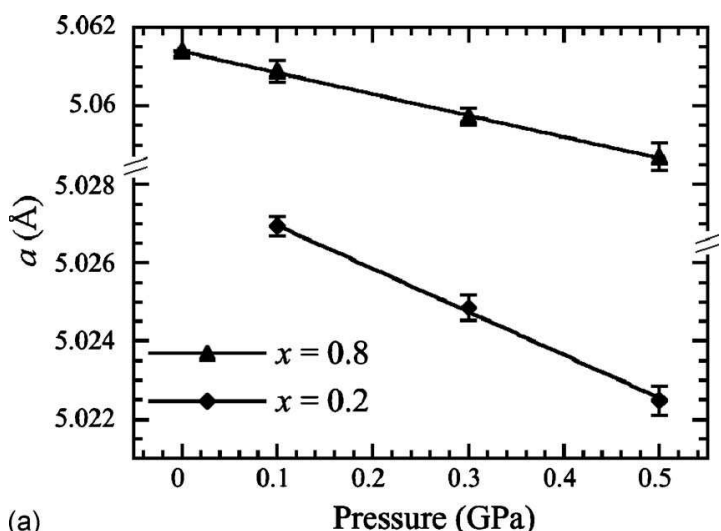

(a)

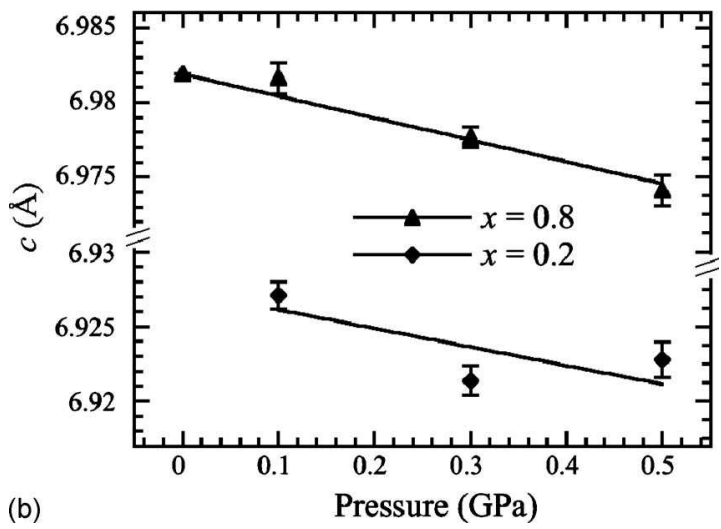

FIG. 4. Pressure evolution of the $a$ lattice parameter (a) and of the $c$ lattice parameter (b) for the $\mathrm{Y}_{1-\mathrm{x}} \mathrm{Th}_{\mathrm{x}} \mathrm{Co}_{4} \mathrm{~B}$ compounds, with $\mathrm{x}=0.8$ and 0.2 , at room temperature.

high value of $T_{\mathrm{C}} \mathrm{d} T_{\mathrm{C}} / \mathrm{d} P$ for the $\mathrm{RCo}_{4} \mathrm{~B}$ compounds ( $\mathrm{R}$ $=$ rare-earth element or $\mathrm{Y}$ ) could be understood by the presence of a non-negligible contribution of the $5 d$ (or $4 d$ ) and $6 s$ (or $5 s$ electrons of $\mathrm{R}$ (or $\mathrm{Y}$, respectively)-elements to the itinerant magnetism of the $3 d$-electrons in the Co sublattice. In the contrast to $\mathrm{R}$, a similar contribution of the $6 d$-and $7 s$-electrons of $\mathrm{Th}$ is almost negligible and the strong decrease in the parameter $T_{\mathrm{C}} \mathrm{d} T_{\mathrm{C}} / \mathrm{d} P$ indicates that the Co sublattice magnetism is evolving toward a more pronounced localized character with the increasing substitution of Th for Y. Using the compressibility parameters determined above, the volume dependence of the Curie temperature has been de-

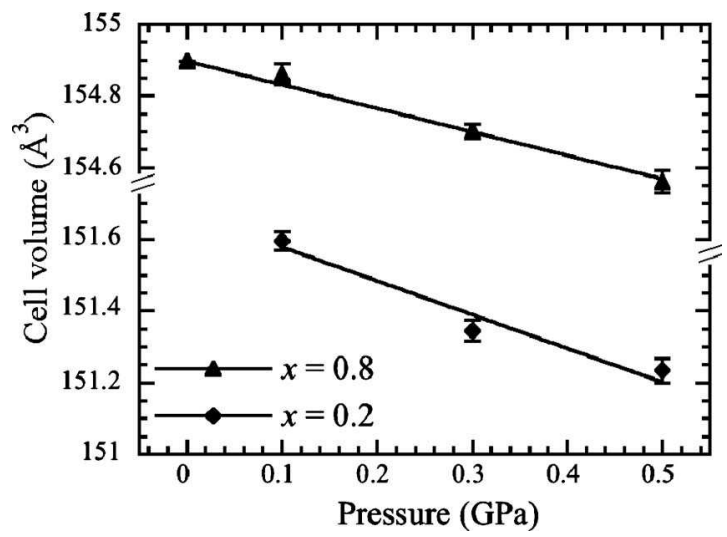

FIG. 5. Pressure evolution of the unit cell volume of the $\mathrm{Y}_{1-\mathrm{x}} \mathrm{Th}_{\mathrm{x}} \mathrm{Co}_{4} \mathrm{~B}$ compounds, with $\mathrm{x}=0.8$ and 0.2 , at room temperature.
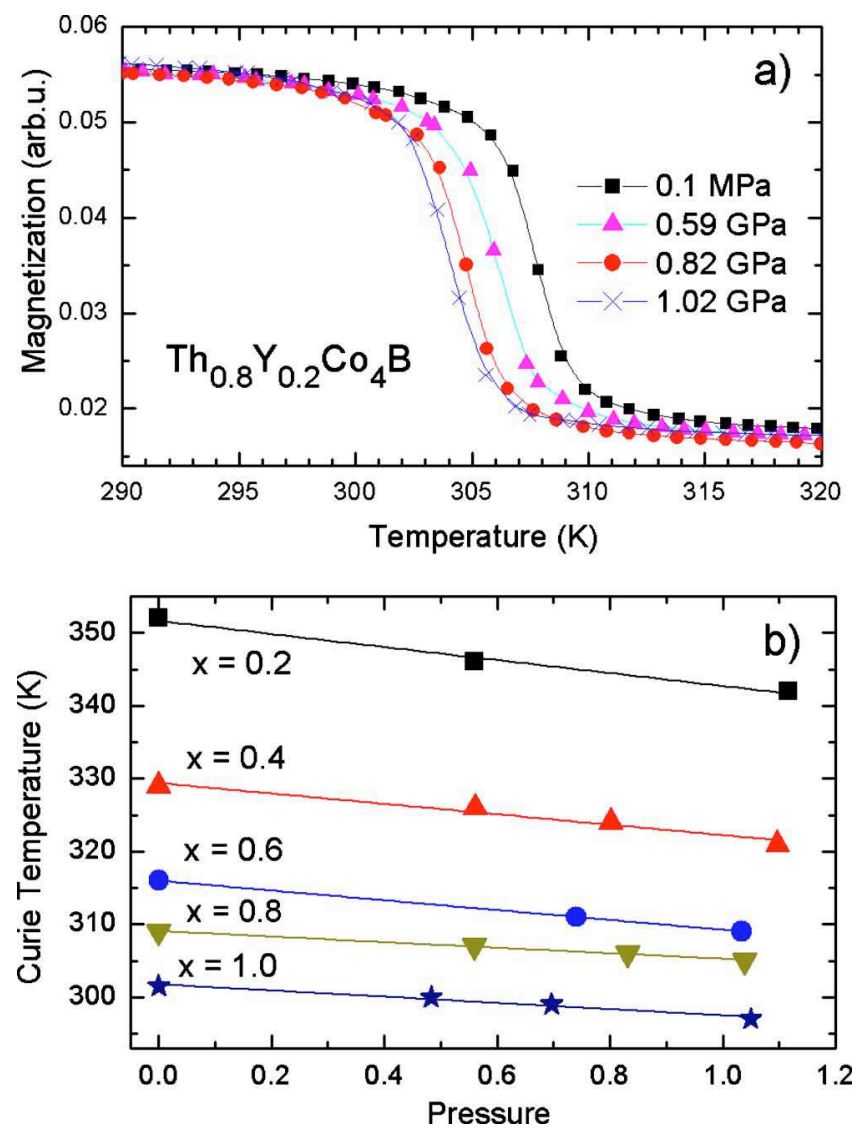

FIG. 6. (Color online) (a) Thermomagnetic measurements at field $10 \mathrm{mT}$ for $\mathrm{Y}_{0.2} \mathrm{Th}_{0.8} \mathrm{Co}_{4} \mathrm{~B}$ at the indicated pressures. (b) Pressure evolution of the Curie temperature of the $\mathrm{Y}_{1-\mathrm{x}} \mathrm{Th}_{\mathrm{x}} \mathrm{Co}_{4} \mathrm{~B}$ polycrystalline samples.

rived. The corresponding values are given in Table I. It can be noticed that both the compressibility and the Curie temperature dependences are much smaller for the Th rich compound. These results may be related since the exchange interactions are known to be dependent upon inter-atomic distances. The consequence of remarkably lower compressibility of the Th rich compound than that of Y rich compound is a significant reduction in the differences between the volume dependences of Curie temperature for Th and $\mathrm{Y}$ rich compounds-see Table I. Practically identical values of $\mathrm{d} T_{\mathrm{C}} / \mathrm{d} P$ for compounds with $\mathrm{x}=0.8$ and $\mathrm{x}=1$ together with

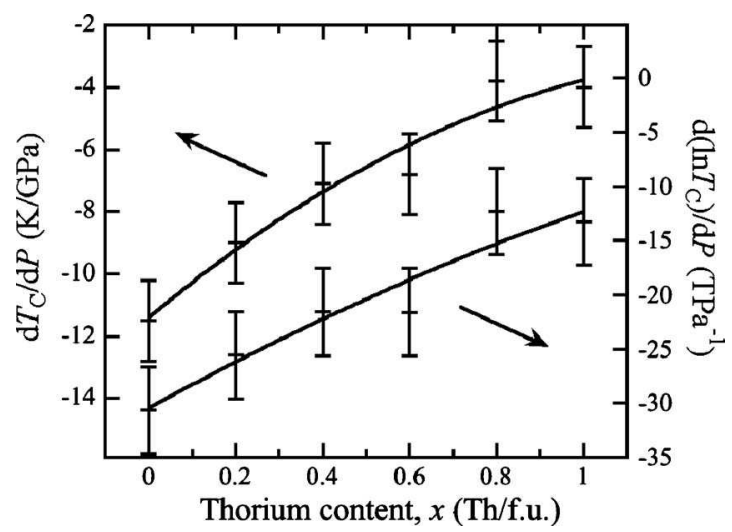

FIG. 7. Dependence of $\mathrm{d} T_{\mathrm{C}} / \mathrm{d} P$ and $\mathrm{d} \ln T_{\mathrm{C}} / \mathrm{d} P$ on composition of the $\mathrm{Y}_{1-\mathrm{x}} \mathrm{Th}_{\mathrm{x}} \mathrm{Co}_{4} \mathrm{~B}$ compounds. 


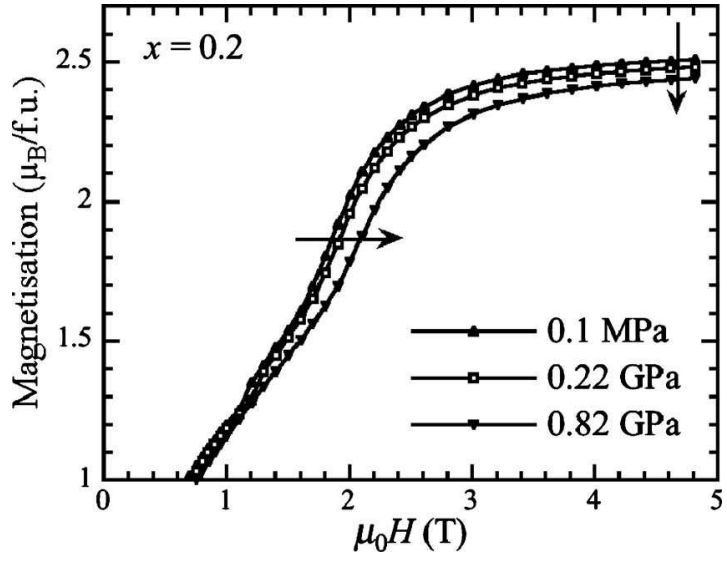

FIG. 8. Pressure evolution of the magnetization isotherms and the first order magnetization like process in the $\mathrm{Y}_{0.8} \mathrm{Th}_{0.2} \mathrm{Co}_{4} \mathrm{~B}$ polycrystalline sample at temperature $5 \mathrm{~K}$.

similar magnetization values at ambient pressure can be an indication of the fact, that magnetic moments of Co $6 \mathrm{i}$ ions are already suppressed in both compounds.

One can remark the decrease in $T_{\mathrm{C}}$ of the $\mathrm{Y}_{1-\mathrm{x}} \mathrm{Th}_{\mathrm{x}} \mathrm{Co}_{4} \mathrm{~B}$ compounds upon applying pressure and corresponding decrease in the unit cell volume. On the contrary at ambient pressure, the reduction in the Curie temperature is induced by replacing $\mathrm{Th}$ for $\mathrm{Y}$ in spite of an expansion of the unit cell. This bears witness to the importance of the electronic influence of the substitution. The effect of Th cannot be consequently reduced to a chemical pressure effect, but, the electronic effect is of prime importance in the $\mathrm{Y}_{1-\mathrm{x}} \mathrm{Th}_{\mathrm{x}} \mathrm{Co}_{4} \mathrm{~B}$ compounds to determine the magnetic properties of the $\mathrm{Co}$ sublattice.

\section{Pressure dependence of the magnetization}

The high magnetocrystalline anisotropy hampers to reach complete magnetic saturation in the $\mathrm{Y}_{1-\mathrm{x}} \mathrm{Th}_{\mathrm{x}} \mathrm{Co}_{4} \mathrm{~B}$ compounds at the magnetic fields used. The shape of magnetization isotherms is not affected by pressure, but as can be seen from Fig. 8, the magnetization is pressure dependent and the logarithmic pressure derivative of the saturation magnetization, $\mathrm{d} \ln M_{\mathrm{S}} / \mathrm{d} P$, can be estimated.

It has been reported earlier that magnetization of the $\mathrm{YCo}_{4} \mathrm{~B}$ compound is very sensitive to the external applied pressure. $^{25,26}$ The value of the logarithmic derivative, $\mathrm{d} \ln M_{\mathrm{S}} / \mathrm{d} P=-33 \times 10^{-3} \mathrm{GPa}^{-1}$, that has been obtained ${ }^{26}$ is of an order of magnitude larger than the pressure effect on the magnetic moment of metallic cobalt. ${ }^{26}$ In the present study, the determined values of $1 / M_{\mathrm{S}} \cdot \mathrm{d} M_{\mathrm{S}} / \mathrm{d} P$ are ranging from $-29 \times 10^{-3} \mathrm{GPa}^{-1}$ to $-32 \times 10^{-3} \mathrm{GPa}^{-1}$ for $\mathrm{Y}_{0.8} \mathrm{Th}_{0.2} \mathrm{Co}_{4} \mathrm{~B}$ and $\mathrm{Y}_{0.2} \mathrm{Th}_{0.8} \mathrm{Co}_{4} \mathrm{~B}$, respectively. In contrast with the pressure dependence of $T_{\mathrm{C}}$, the pressure coefficient of the magnetization is only slightly sensitive to the Th concentration (see Table I). The determined values of $\mathrm{d} \ln M_{\mathrm{S}} / \mathrm{d} P$ are similar not only to those reported earlier for $\mathrm{YCo}_{4} \mathrm{~B}$ but also to the more recently presented values for $\mathrm{YCo}_{4} \mathrm{Si} \quad\left(-33 \times 10^{-3} \mathrm{GPa}^{-1}\right.$ and $-30(5) \times 10^{-3} \mathrm{GPa}^{-1}$, respectively $\left.{ }^{22,26,47}\right)$. Such high values of $\mathrm{d} \ln M_{\mathrm{S}} / \mathrm{d} P$ can be interpreted as a confirmation of the dominant itinerant character of the $\mathrm{Co}$ magnetic moment in $\mathrm{RCo}_{4} \mathrm{~B}$. It is worth to

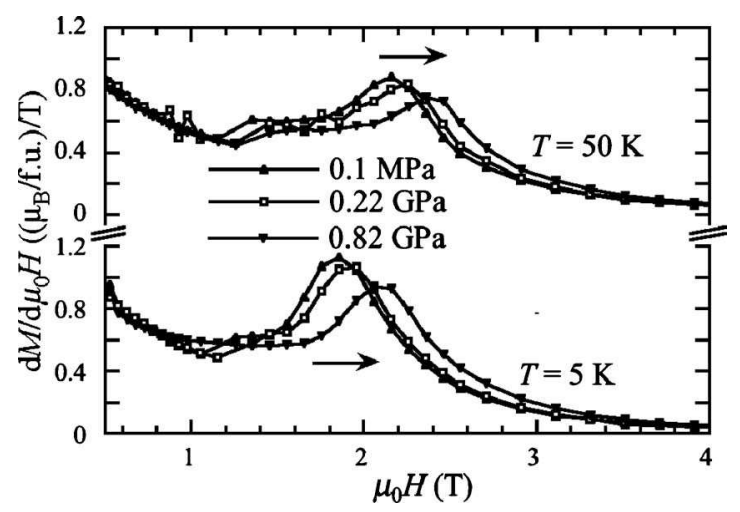

FIG. 9. Pressure evolution of the critical field of the FOMP in the $\mathrm{Y}_{0.8} \mathrm{Th}_{0.2} \mathrm{Co}_{4} \mathrm{~B}$ polycrystalline sample at the indicated temperatures.

recall that for the largest Th concentration the large anisotropy hampers to saturate the sample and the obtained values of the logarithmic pressure derivative are in these cases rather qualitative. The pressure induced decrease in magnetization of studied compounds is slightly more pronounced at increasing temperature as a consequence of the decrease in $T_{\mathrm{C}}$ with pressure. At $200 \mathrm{~K}$, the corresponding logarithmic pressure derivatives are ranging between -33 and -44 $10^{-3} \mathrm{GPa}^{-1}$ for the $\mathrm{Y}_{1-\mathrm{x}} \mathrm{Th}_{\mathrm{x}} \mathrm{Co}_{4} \mathrm{~B}$ compounds.

\section{Pressure effects on the critical field in $\mathrm{Y}_{0.8} \mathrm{Th}_{0.2} \mathrm{Co}_{4} \mathrm{~B}$}

The disappearance of the FOMP-like behavior for the $\mathrm{Y}_{1-\mathrm{x}} \mathrm{Th}_{\mathrm{x}} \mathrm{Co}_{4} \mathrm{~B}$ compounds with composition $\mathrm{x}>0.2$ may be taken as an indication that this phenomenon reflects the interplay between the $2 \mathrm{c}$ and $6 \mathrm{i}$ Co-site contribution to the magnetocrystalline anisotropy. Indeed, the 6i Co-site contribution to the magnetization has been found to vanish when replacing $\mathrm{Y}$ by $\mathrm{Th}$. Consequently, a reduction in the $6 \mathrm{i} \mathrm{Co-}$ sites contribution to the magnetocrystalline anisotropy and the disappearance of the spin reorientation are expected replacing $\mathrm{Y}$ by Th atoms. Following this expectation, the magnetocrystalline anisotropy behavior of the $\mathrm{Y}_{0.8} \mathrm{Th}_{0.2} \mathrm{Co}_{4} \mathrm{~B}$ compound should be controlled by the $2 \mathrm{c}$ Co-site mainly. One can thus suppose that the behavior of anisotropy of $\mathrm{Y}_{0.8} \mathrm{Th}_{0.2} \mathrm{Co}_{4} \mathrm{~B}$ is similar to that of $\mathrm{YCo}_{4} \mathrm{~B}$ at high temperature when the $2 \mathrm{c} \mathrm{Co-sublattice} \mathrm{contribution} \mathrm{to} \mathrm{the} \mathrm{anisotropy}$ dominates over the 6i Co-sublattice. Indeed, this is what happens since, for the $\mathrm{Y}_{0.8} \mathrm{Th}_{0.2} \mathrm{Co}_{4} \mathrm{~B}$ compound, the critical field of the FOMP-like magnetization process increases with increasing temperature by the same way as in $\mathrm{YCo}_{4} \mathrm{~B}$ above the spin reorientation temperature. ${ }^{22}$ As can be seen from Figs. 8 and 9, the critical field at which the FOMP-like behavior manifests itself is found to be pressure dependant. Moreover, the pressure evolution of the critical field in $\mathrm{Y}_{0.8} \mathrm{Th}_{0.2} \mathrm{Co}_{4} \mathrm{~B}$ is linear versus pressure as observed in the case of $\mathrm{YCo}_{4} \mathrm{~B}$ above the spin reorientation. ${ }^{22}$ At $5 \mathrm{~K}$, this critical field increases from $1.86 \mathrm{~T}$ to $2.07 \mathrm{~T}$ when the applied pressure increases from $0 \mathrm{GPa}$ up to $0.8 \mathrm{GPa}$, respectively. It is remarkable that this pressure induced increase in the critical field corresponding to the anomalous magnetization process is almost the same at 5 and $50 \mathrm{~K}$. The pressure derivative of $\mathrm{d} H_{\mathrm{C}} / \mathrm{d} P$ is found to be $0.26(5) \mathrm{T} / \mathrm{GPa}$ and $0.32(5) \mathrm{T} / \mathrm{GPa}$ at $5 \mathrm{~K}$ and $50 \mathrm{~K}$, respectively. These values 
can be compared to that of $\mathrm{YCo}_{4} \mathrm{~B}$ above the spin reorientation transition, where value of $\mathrm{d} H_{\mathrm{C}} / \mathrm{d} P=0.3 \mathrm{~T} / \mathrm{GPa}$ has been obtained. ${ }^{22}$

\section{DISCUSSION}

In $\mathrm{YCo}_{4} \mathrm{~B}$, neutron diffraction ${ }^{3,9}$ has shown that the $2 \mathrm{c}$ Co-site carries a much larger magnetic moment than the $6 \mathrm{i}$ Co-sites. Both neutron diffraction and band structure calculations have demonstrated that $\mathrm{Th}$ for $\mathrm{Y}$ replacement dramatically influences the magnetic moment on the $6 \mathrm{i}$ Co-site. ${ }^{19}$ Indeed, the magnetic moment carried on the $6 \mathrm{i}$ Co-site in $\mathrm{ThCo}_{4} \mathrm{~B}$ has been reported to be barely nil. On the contrary, the 2c Co-site is not much affected by the Th for $\mathrm{Y}$ replacement. For the large Th concentration in $\mathrm{Y}_{1-\mathrm{x}} \mathrm{Th}_{\mathrm{x}} \mathrm{Co}_{4} \mathrm{~B}$ solid solution, the 6i Co-site magnetization being negligible, the magnetic features reported here can be ascribed to the $2 \mathrm{c}$ Co-sublattice only. When comparing the pressure sensitivity of the Y rich to that of the Th rich compound one can assume that the observed difference in pressure behavior of these compounds represents the 6i Co-site sensitivity only since the magnitude of 2c magnetic Co moment is not affected by the Th for $\mathrm{Y}$ substitution. According to the large difference in $\mathrm{d} T_{\mathrm{C}} / \mathrm{d} P$ observed for the $\mathrm{YCo}_{4} \mathrm{~B}$ and $\mathrm{ThCo}_{4} \mathrm{~B}$ compound, respectively, one can expect the $6 \mathrm{i} \mathrm{Co}$-sublattice contribution to the Curie temperature of $\mathrm{YCo}_{4} \mathrm{~B}$ to be more sensitive to the pressure than the 2c Co-sublattice one. On the one hand, one has to recall that both Co sublattices are carrying about the same magnetization in $\mathrm{YCo}_{4} \mathrm{~B}$, on the other hand, already in the related ferromagnetic $\mathrm{ThCo}_{5}$ compound, the Co $3 \mathrm{~g}$ site exhibits a lower magnetic state leading to unusual metamagnetic transition. ${ }^{38,40}$ The metamagnetic transition takes place when the Co atoms at the $3 \mathrm{~g}$ site become magnetic under the magnetic field, a transition which has been found to be very sensitive to the applied pressure. ${ }^{39}$

The larger pressure sensitivity of the corresponding $6 \mathrm{i}$ Co-site may be related to the difference in the local atomic environment of the Co-sites since the presence of boron atoms in the neighborhood of the 6i Co-site leads to strong hybridization of the Co and B electronic states. One can thus assume that applying pressure should strengthen this hybridization by decreasing the $6 \mathrm{i} \mathrm{Co}-\mathrm{B}$ distances thus favoring a reduction in the Co magnetic moment on the 6i sites. Obviously, the 2c Co-sites which have not boron as the nearest neighbors should not experience such electronic effect of pressure.

This discussion also requires the precise knowledge of the crystal structure and its evolution with composition. Consequently, crystallographic investigation will be carried out by $\mathrm{x}$-ray diffraction and analysis will enable to check the possibility of preferential substitution scheme in the $\mathrm{Y}_{1-\mathrm{x}} \mathrm{Th}_{\mathrm{x}} \mathrm{Co}_{4} \mathrm{~B}$ solid solution. Indeed one has to keep in mind that the two inequivalent atomic positions for $\mathrm{R}$ are present in the $\mathrm{RCo}_{4} \mathrm{~B}$ type structure. The replacement of trivalent $\mathrm{Y}$ atoms by tetravalent Th atom may have a significant influence on the physical properties. The determination of the Th location within the lattice is thus of importance and this will be the aim of a further work.

The FOMP-like behavior is present in $\mathrm{Y}_{0.8} \mathrm{Th}_{0.2} \mathrm{Co}_{4} \mathrm{~B}$, but, it disappears in the compounds with the larger Th content. This reflects that the magnetocrystalline anisotropy parameters are significantly changed upon Th for Y substitution. The critical field at which this unusual FOMP-like behavior occurs in $\mathrm{Y}_{0.8} \mathrm{Th}_{0.2} \mathrm{Co}_{4} \mathrm{~B}$ is temperature as well as pressure dependent. The $\mathrm{YCo}_{4} \mathrm{~B}$ compound can be regarded as a sample of intermetallics that is very sensitive to the external pressure in comparison with the Th containing isotype compounds. Large sensitivity of the Co sublattice magnetic properties to external excitation like temperature, field, and pressure has been observed.

\section{CONCLUSIONS}

The values of pressure derivatives of both the Curie temperature and the magnetization are negative for all the $\mathrm{Y}_{1-\mathrm{x}} \mathrm{Th}_{\mathrm{x}} \mathrm{Co}_{4} \mathrm{~B}$ compounds series. This is opposite to the positive effect expected from the unit cell volume increase occurring upon Th for Y substitution. This clearly supports the dominant effect of valence electrons on the magnetic properties of the substituted $\mathrm{Y}_{1-\mathrm{x}} \mathrm{Th}_{\mathrm{x}} \mathrm{Co}_{4} \mathrm{~B}$ compound with respect to the chemical pressure effect. In order to quantify the electronic effect, band structure calculations are necessary. Whereas the substitution of Th for Y induces a strong reduction in the Curie temperature and the magnetization, the pressure dependence of magnetization is almost the same in all the $\mathrm{Y}_{1-\mathrm{x}} \mathrm{Th}_{\mathrm{x}} \mathrm{Co}_{4} \mathrm{~B}$ compounds. This indicates that the magnetism of the Co-sublattice plays clearly dominating role in the sensitivity of magnetization to external pressure. On the contrary, the sensitivity of the Curie temperature to external pressure is much higher in the $\mathrm{Y}$ rich compounds than in the Th rich ones which bear witness to the electronic influence of Th in this case.

The spin reorientation presented in $\mathrm{YCo}_{4} \mathrm{~B}$ disappears in the $\mathrm{Y}_{1-\mathrm{x}} \mathrm{Th}_{\mathrm{x}} \mathrm{Co}_{4} \mathrm{~B}$ compounds with $\mathrm{x}<0.2$. The FOMP occurs only for $\mathrm{Y}_{0.8} \mathrm{Th}_{0.2} \mathrm{Co}_{4} \mathrm{~B}$. The pressure dependence of the critical field at which this FOMP phenomenon occurs has been analyzed and discussed. Whereas $\mathrm{YCo}_{4} \mathrm{~B}$ has been described as the unique compound where the FOMP is associated with the Co sublattice only, we have shown here that $\mathrm{Y}_{0.8} \mathrm{Th}_{0.2} \mathrm{Co}_{4} \mathrm{~B}$ also exhibits such unusual magnetic behavior. According to the room temperature neutron diffractions, the lattice parameters decrease linearly in the pressure range up to $0.5 \mathrm{GPa}$. The substitution of Th for $\mathrm{Y}$ induces a significant reduction in the $\mathrm{Y}_{1-\mathrm{x}} \mathrm{Th}_{\mathrm{x}} \mathrm{Co}_{4} \mathrm{~B}$ lattice compressibility.

Further magnetic studies of the $\mathrm{Y}_{1-\mathrm{x}} \mathrm{Th}_{\mathrm{x}} \mathrm{Co}_{4} \mathrm{~B}$ compounds at high magnetic field are necessary to saturate the magnetization of all the samples and to determine accurately the saturation magnetization as well as the anisotropy parameters. In order to better understand the magnetic properties of the Co sublattice at a microscopic scale, low neutron diffraction experiments would be necessary.

\section{ACKNOWLEDGMENTS}

The financial support of the project 202/09/1027 GA CR and that of the CNRS-ASRT cooperation Program No. 18115 is also warmly acknowledged.

${ }^{1}$ Yu. B. Kuz'ma and N. S. Bilonizko, Sov. Phys. Crystallogr. 18, 447 
(1974).

${ }^{2}$ Yu. B. Kuz'ma, Crystal chemistry of borides (Lviv University, Ukraine, 1983), in Russian.

${ }^{3}$ C. Chacon and O. Isnard, J. Phys.: Condens. Matter 13, 5841 (2001).

${ }^{4}$ C. Zlotea, C. Chacon, and O. Isnard, J. Appl. Phys. 92, 7382 (2002).

${ }^{5}$ A. Szajek, J. Magn. Magn. Mater. 185, 322 (1998).

${ }^{6}$ O. Isnard and C. Chacon Carillo, J. Alloys Compd. 442, 22 (2007).

${ }^{7}$ E. Burzo, V. Pop, C. C. Borodi, and R. Ballou, IEEE Trans. Magn. 30, 628 (1994).

${ }^{8}$ H. Ogata, H. Ido, and H. Yamauchi, J. Appl. Phys. 73, 5911 (1993).

${ }^{9}$ C. Chacon and O. Isnard, J. Appl. Phys. 89, 71 (2001).

${ }^{10}$ H. Yamada, K. Terao, H. Nakazawa, I. Kitagawa, N. Suzuki, and H. Ido, J. Magn. Magn. Mater. 183, 94 (1998).

${ }^{11}$ Cz. Kapusta, M. Rosenberg, and K. H. J. Buschow, J. Alloys Compd. 187, 409 (1992).

${ }^{12}$ E. Burzo, J. Magn. Magn. Mater. 196-197, 901 (1999).

${ }^{13}$ E. Burzo and M. Ursu, J. Magn. Magn. Mater. 70, 345 (1987).

${ }^{14}$ A. T. Pedziwiatr, S. Y. Jiang, W. E. Wallace, E. Burzo, and V. Pop, J. Magn. Magn. Mater. 66, 69 (1987).

${ }^{15}$ C. Chacon and O. Isnard, J. Solid State Chem. 154, 242 (2000).

${ }^{16}$ H. Ido, K. Sugiyama, H. Hachino, M. Date, S. F. Cheng, and K. Maki, Physica B 177, 265 (1992).

${ }^{17}$ N. P. Thuy, N. M. Hing, J. P. Liu, X. Li, J. J. M. Franse, and F. R. de Boer, Physica B 177, 270 (1992).

${ }^{18}$ O. Isnard, V. Pop, and J. C. Toussaint, Proceedings of the High performance Magnet and their Applications, Annecy, 29 August-2 September 2004, Vol. 2, p. 549.

${ }^{19}$ D. Benea, V. Pop, and O. Isnard, J. Magn. Magn. Mater. 320, 36 (2008).

${ }^{20}$ A. Szajek, Acta Phys. Pol. A 113, 283 (2008).

${ }^{21}$ C. Chacon, O. Isnard, L. Chioncel, C. Giorgetti, F. Baudelet, and E. Dartyge, J. Magn. Magn. Mater. 242-245, 861 (2002).

${ }^{22}$ H. Mayot, O. Isnard, Z. Arnold, and J. Kamarad, J. Phys.: Condens. Matter 20, 135207 (2008).

${ }^{23}$ N. M. Hong, N. P. Thuy, T. D. Hien, G. Hilscher, T. S. Zhao, and G. Grössinger, J. Appl. Phys. 73, 5917 (1993).

${ }^{24}$ C. V. Thang, P. E. Brommer, N. P. Thuy, and J. J. M. Franse, J. Magn. Magn. Mater. 171, 237 (1997).

${ }^{25}$ J. Kamarad, Z. Arnold, O. Mikulina, V. Sechovsky, H. Ido, and N. M.
Hong, Physica B 237-238, 527 (1997).

${ }^{26}$ Z. Arnold, J. Kamarad, Y. Skorokhod, N. M. Hong, N. P. Thuy, and C. V. Thang, J. Magn. Magn. Mater. 262, 382 (2003).

${ }^{27}$ J. M. Cadogan, L. Hong-Shuo, S. J. Campbell, and J. Jing, Sol. State Comm. 81, 121 (1992).

${ }^{28}$ G. J. Long, R. P. Hermann, F. Grandjean, C. Chacon, and O. Isnard, J. Phys.: Condens. Matter 18, 10765 (2006).

${ }^{29}$ F. Grandjean, M. T. Sougrati, H. Mayot, O. Isnard, and G. J. Long, J. Phys.: Condens. Matter 21, 186001 (2009).

${ }^{30}$ Cz. Kapusta, N. Spiridis, and H. Figiel, J. Magn. Magn. Mater. 83153 (1990).

${ }^{31}$ I. Kitagawa and N. Suzuki, J. Magn. Magn. Mater. 177-181, 1357 (1998).

${ }^{32}$ O. Isnard, V. Pop, and J. C. Toussaint, J. Phys.: Condens. Matter 15, 791 (2003).

${ }^{33}$ C. V. Thang, Ph.D. thesis, Universiteit van Amsterdam, 1996.

${ }^{34}$ H. Mayot, O. Isnard, Z. Arnold, and J. Kamarad, High Press. Res. 26, 489 (2006).

${ }^{35}$ A. Barlet, J. C. Genna, and P. Lethuillier, Cryogenics 31, 801 (1991).

${ }^{36}$ J. Kamarád, Z. Machátováa, and Z. Arnold, Rev. Sci. Instrum. 75, 5022 (2004).

${ }^{37}$ H. Mayot, Ph.D. thesis, Université Joseph Fourier de Grenoble, 2008.

${ }^{38}$ D. Givord, J. Laforest, R. Lemaire, and Q. Lu, J. Magn. Magn. Mater. 31-34, 191 (1983).

${ }^{39}$ R. Ballou, M. Shimizu, and J. Voiron, J. Magn. Magn. Mater. 84, 23 (1990).

${ }^{40}$ L. Nordström, B. Johansson, O. Eriksson, and M. S. S. Brooks, Phys. Rev. B 42, 8367 (1990).

${ }^{41}$ G. Asti and F. Bolzoni, J. Magn. Magn. Mater. 20, 29 (1980).

${ }^{42}$ G. Asti, in Ferromagnetic Materials, edited by K. H. J. Buschow and E. P. Wohlfarth (Elsevier, Amsterdam, 1990), Vol. 5.

${ }^{43}$ O. Isnard, V. Pop, M. Guillot, H. Mayot, and J. C. Toussaint in preparation.

${ }^{44}$ Z. Arnold, N. M. Hong, Y. Skorokhod, and Z. Machatova, Physica B 327, 211 (2003).

${ }^{45}$ E. P. Wohlfarth, Solid State Commun. 35, 797 (1980).

${ }^{46}$ J. Inoue and M. Shimizu, Phys. Lett. A 90A, 85 (1982).

${ }^{47}$ O. Isnard, Z. Arnold, N. Coroian, and J. Kamarad, J. Magn. Magn. Mater. 316, 325 (2007). 